\title{
THE TIME SERIES OF TERRA AND AQUA MODIS NEAR-IR WATER VAPOR PRODUCTS
}

\author{
Bo-Cai Gao ${ }^{1 *}$, and Rong-Rong $\mathrm{Li}^{1}$ \\ Remote Sensing Division, Naval Research Laboratory, Washington, DC USA; gao@nrl.navy.mil
}

\begin{abstract}
Two Moderate Resolution Imaging SpectroRadiometer (MODIS) instruments [1] on the NASA Terra and Aqua Spacecraft platforms are currently operational for global remote sensing of the land, ocean and atmosphere. Both MODIS instruments are equipped with channels located within and around the 0.94-micron water vapor band absorption region for water vapor measurements over reflective land surfaces, clouds, and oceanic regions with sunglint. We have developed an algorithm to retrieve column water vapor amount using ratios of water vapor absorption channels with nearby atmospheric window channels [2]. The daily 'pixel-based' Level 2 near-IR water vapor product at the 1-km spatial resolution of the MODIS instrument, and the daily, 8-day, and monthly-mean Level 3 near-IR water vapor products at a $1^{\circ}$ by $1^{\circ}$ latitude-longitude grid globally are routinely produced at a NASA computing facility [3]. We have analyzed more than eight years of Terra MODIS and five years of Aqua MODIS Level 3 monthly-mean near-IR water vapor products. Major observations on spatial distributions and temporal variations of water vapor in different geographic regions are described in this paper. Areas severely affected by the 2002 El Nino phenomenon in southeastern Australia and southeastern Asia can be detected from the Level 3 monthly-mean data sets. The 2007 drought areas in southeastern US can also be seen. It is concluded that the MODIS near-IR water vapor products can be useful for establishing a long term water vapor climatology over global land surface areas.
\end{abstract}

\section{Index Terms - MODIS, water vapor}

\section{INTRODUCTION}

Hydrological processes play an important role in weather and climate by determining the energetics and dynamics. Yet many aspects of the hydrological processes are not well understood and there are still large uncertainties in various hydrologic parameters, particularly over data sparse areas such as the oceans and remote land areas [4]. Total precipitable water (TPW) is the amount of liquid water that would result if all the water vapor in the atmospheric column of unit area were condensed. TWP is also referred as column water vapor amount. TPW distribution contains valuable information on the vigor of the hydrological processes and moisture transport in the atmosphere. Accurate global measurement, modeling and long-term prediction of water vapor is the primary goal of the Global Water Vapor Project which is a component of GEWEX (Global Energy and Water Cycle Experiment). Long-term global measurement of TPW will be useful in studying the global hydrological cycle, documenting seasonal and inter-annual variations, and verifying model output. It is well known that time series of TPW over the ocean [5] can be retrieved from satellite-based microwave emission measurements, but not over land because of large uncertainties in microwave emissivities of land surfaces. The deficiency over land can be remedied with satellite-based near-IR water vapor measurements [6].

Table 1: The five MODIS near-IR channels used in water vapor retrievals.

$\begin{array}{ll}\text { MODIS Cannel \# } & \text { Positi } \\ & \\ 2 & 0.865 \\ 5 & 1.24 \\ 17 & 0.905 \\ 18 & 0.936 \\ 19 & 0.940\end{array}$

At present, two MODIS instruments on board the NASA Terra and Aqua Spacecraft platforms are operational for global remote sensing of the land, ocean and atmosphere. MODIS has 36 channels covering the spectral region between 0.4 and $15 \mu \mathrm{m}$. Five near-IR channels in the $0.8-1.3 \mu \mathrm{m}$ spectral region are useful for remote sensing of water vapor. The MODIS near-IR water vapor algorithm relies on observations of water vapor attenuation of solar radiation reflected by the bottom surface. Techniques employing ratios of water vapor absorbing channels centered near 0.905 , 0.936 , and $0.940 \mu \mathrm{m}$ with atmospheric window channels at 0.865 and $1.24 \mu \mathrm{m}$ are used. The ratios effectively remove the effects of variation of surface reflectance with wavelengths and result in the atmospheric water vapor transmittances. The column water vapor amounts are derived from the transmittances based on theoretical calculations and the use of look-up table procedures. The daily 'pixel-based' near-IR water vapor product, which is a standard MODIS Level 2 data product, at the $1-\mathrm{km}$ spatial resolution of the MODIS instrument, and the daily, 8-day, and monthly near-IR water vapor products, which are standard MODIS Level 3 products, at a $1^{\circ}$ by $1^{\circ}$ latitude-longitude grid globally are now routinely produced at a NASA computing facility. The 
MODIS water vapor measurements over land complement the microwave water vapor measurements over ocean.

At present, more than eight years of Terra MODIS and five years of Aqua MODIS Level 3 monthly-mean near-IR water vapor products have been generated. Through analysis of these time series of water vapor products, we have observed major spatial and temporal variation patterns of water vapor over different geographical regions. Some of our observations are described below.

\section{WATER VAPOR DATA CUBE}

A standard MODIS Atmosphere Level 3 monthly-mean data set in HDF format contains several hundred parameters. The near-IR water vapor parameter is one of the parameters packed inside a large HDF file. In order to facilitate the analysis of MODIS near-IR water vapor data over several years, we first extracted the monthly-mean near-IR water vapor image for each month from the HDF file and stored the image in a single binary file. We then stacked the separate water vapor images together to form a three dimensional water vapor data cube. The $\mathrm{X}, \mathrm{Y}$, and $\mathrm{Z}$ dimensions of the data cube correspond to longitude, latitude, and month, respectively. We have generated a Terra near-IR water vapor data cube for 98 months starting from February 2000 to March 2008, and an Aqua data cube for 69 months starting from July 2002 to March 2008. The 3-dimensional water vapor data cubes have permitted us to explore the spatial and temporal variations of water vapor distributions in different geographic regions.

\section{SAMPLE RESULTS}

Figure 1 shows a time series of column water vapor values over an area in southeastern part of the United States (Latitude: $33^{\circ} \mathrm{N}$; Longitude: $84^{\circ} \mathrm{W}$ ). The last peak in the plot is significantly smaller than the previous two peaks. In general, the water vapor values for the 2007 summer months are much smaller than those of the previous two years. The observation is consistent with the fact that 2007 was a particular dry year for the southeastern part of US.

Figure 2 shows examples of water vapor variations over an area in Amazon and another area in Andes Mountains in South America. The column water vapor amount over this Amazon area remains at about $5.2 \mathrm{~cm}$ through out the years with little variations. The column water vapor amount over the nearby dry Andes Mountains area is generally small (less than about $1 \mathrm{~cm}$ ) but seasonal variations from a low value of approximately $0.2 \mathrm{~cm}$ to a high value of about $1 \mathrm{~cm}$ are observed. Fig. 1 and Fig. 2 have demonstrated that reliable observations of water vapor in different geographic regions over several years can be made with MODIS near-IR channels.

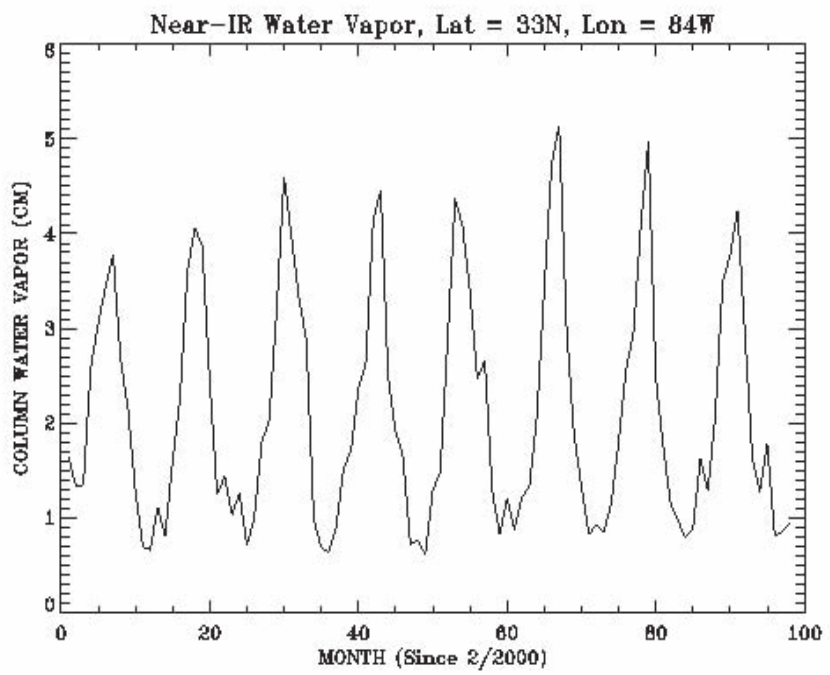

Fig. 1. A time series of monthly-mean column water vapor values over an area in southeastern US from Feb. 2000 to March 2008.

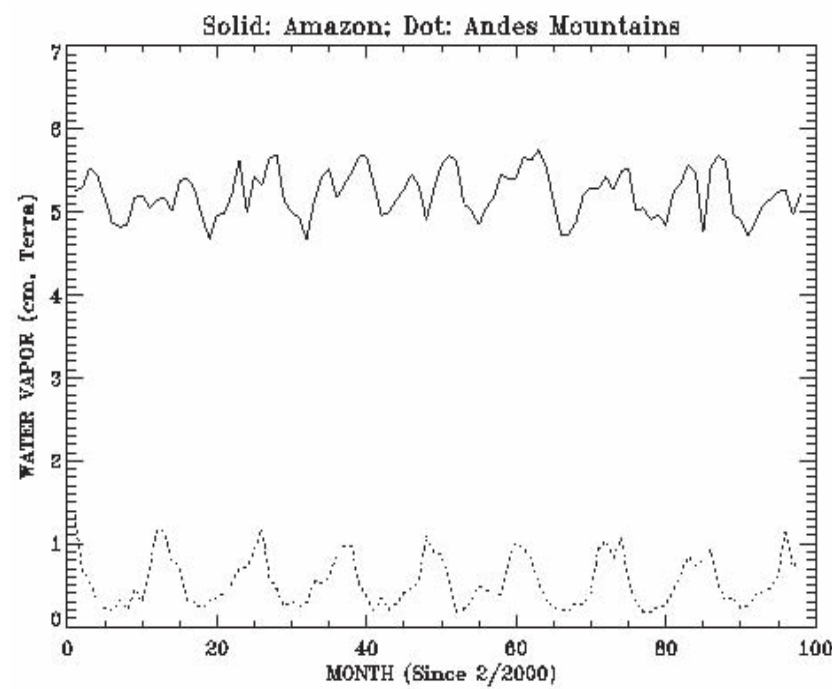

Fig. 2. Time series of monthly-mean water vapor amounts over an area in Amazon and another area in Andes Mountains in South America.

Figure 3 shows sample water vapor variations over an area in northern Australia and another area in southeastern Australia. The northern Australia is located in the tropical region. During the austral summer months, the column water vapor amounts in northern Australia can be quite large ( $>5$ $\mathrm{cm}$ ). Unlike the Amazon case in Fig. 2, the water vapor distributions in northern Australia have significant seasonal variations. The water vapor amounts in southeastern Australia are mostly smaller than $2 \mathrm{~cm}$ and also have obvious seasonal variations. 


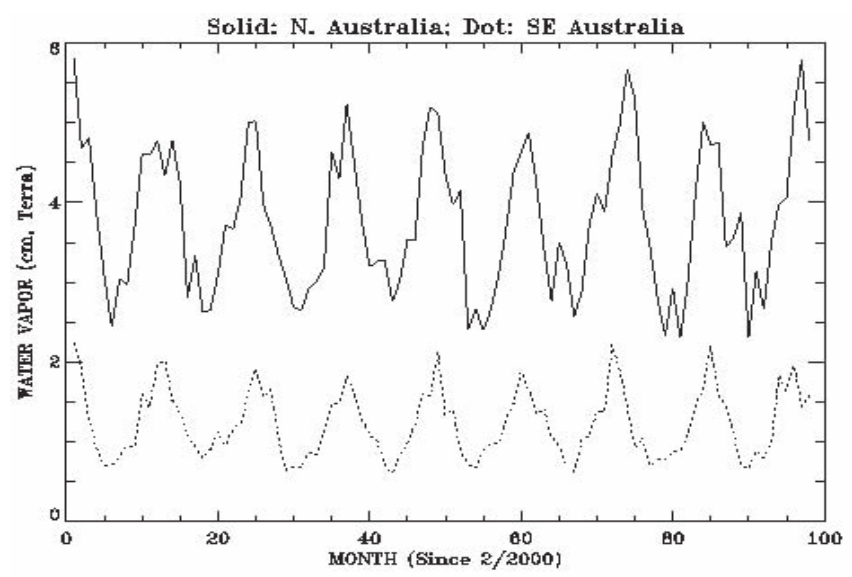

Fig. 3. Time series of monthly-mean column water vapor measurements over an area in northern Australia and another area in southeastern Australia.

At present, more than 8 years of Terra MODIS near-IR water vapor products are available. The water vapor values over a given region can vary in different years. We have averaged 8 monthly mean values for a given month in each year and created an 8-year monthly mean water vapor climatology. We have subtracted out this mean water vapor climatology from the Terra water vapor data cube described in Section 2 and created a new water vapor "deviation" cube. Abnormal water vapor distribution patterns associated with special natural phenomena can be observed from the "deviation" cube.

Figure 4 shows a water vapor "deviation" image of Asia for December 2001. Over the Philippines and southeastern China, the water vapor values were significantly smaller in comparison with those of the 8-year climatology because of the $2001-2002$ El Nino. Figure 5 shows another water vapor "deviation" image over Australia for January 2002. The southeastern portions of Australia were significantly drier in comparison with the 8-year climatology due to the on going El Nino.

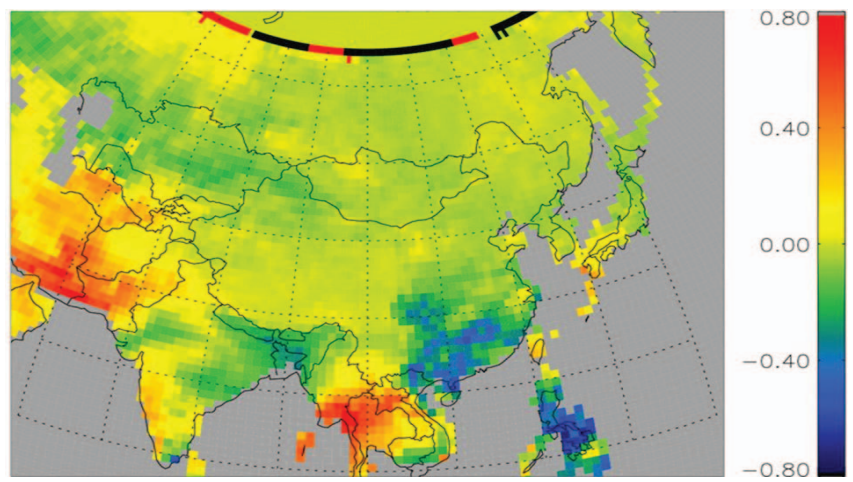

Fig. 4. A water vapor "deviation" image over Asia for December 2001. The unit for the color bar is $\mathrm{cm}$.

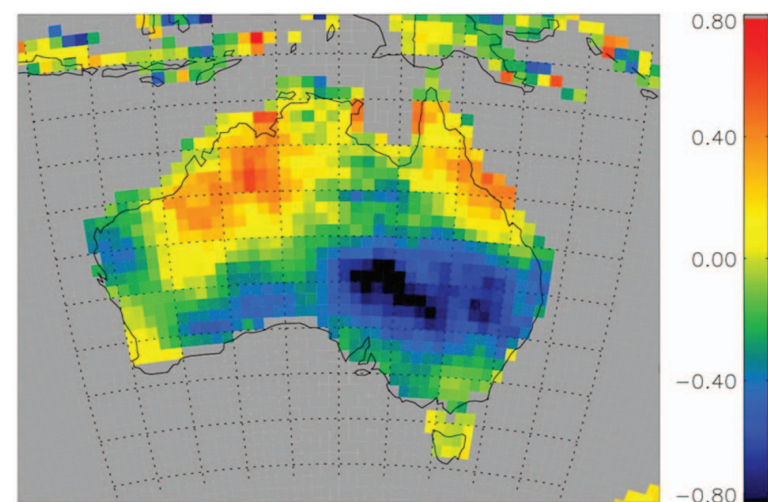

Fig. 5. A water vapor "deviation" image over Australia for January 2002. The unit for the color bar is $\mathrm{cm}$. The southeastern portions of Australia were significantly drier in comparison with the 8-year climatology because of the 20012002 El Nino.

Figure 6 is a water vapor deviation image of the United States for June 2006. Large areas around the Gulf of Mexico in southern US were unusually dry for the month. Figure 7 is another water vapor deviation image, but for July 2007. Many states in southeastern portions of US were significantly drier in comparison with the 8-year climatology.

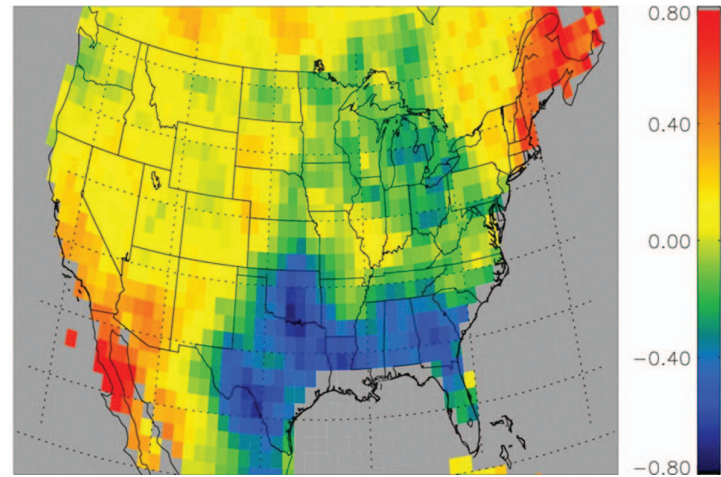

Fig. 6. A water vapor "deviation" image over the United States for June 2006. The unit for the color bar is $\mathrm{cm}$.

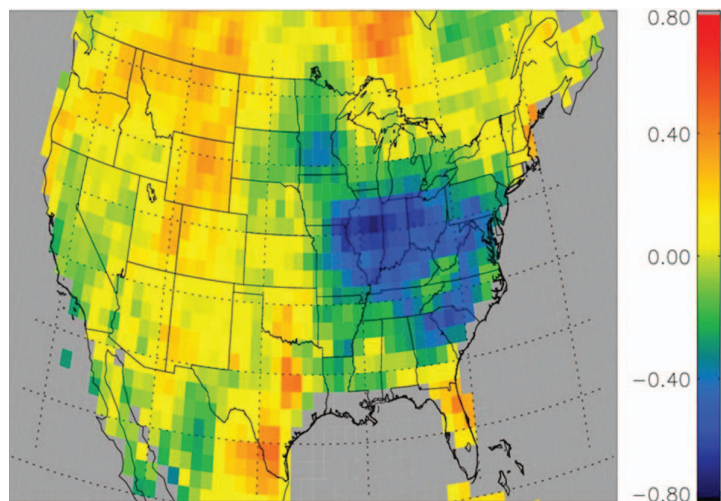

Fig. 7. A water vapor "deviation" image over the United States for July 2007. The unit for the color bar is $\mathrm{cm}$. 


\section{SUMMARY}

We have analyzed more than eight years of Terra MODIS and five years of Aqua MODIS Level 3 monthly-mean nearIR water vapor products. Major observations on spatial distributions and temporal variations of water vapor in different geographic regions are described. Areas severely affected by the 2002 El Nino phenomenon in southeastern Australia and southeastern Asia can be observed easily from the Level 3 monthly-mean data sets. The 2007 drought areas in southeastern US can also be identified easily. The MODIS near-IR water vapor products contain rich information on seasonal and global variations of water vapor over land surfaces and can complement the microwave measurements of water vapor over global ocean.

\section{REFERENCES}

[1] V. V. Salomonson, W. L. Barnes, P. W. Maymon, H.E. Montgomery, and H. Ostrow, "MODIS: Advanced facility instrument for studies of the earth as a system," IEEE Trans. Geosci. Remote Sens., 27, 145-153, 1989.

[2] B.-C. Gao, and Y. J. Kaufman, "Water vapor retrievals using Moderate Resolution Imaging Spectrometer (MODIS) near-IR channels," J. Geophys. Res., 108, 4389 - 4398, 2003.

[3] M. D. King, W. P. Menzel, Y. J. Kaufman, D. Tanre, B.C. Gao, S. Platnick, S. A. Ackerman, L. A. Remer, R. Pincus, and P. A. Hubanks, "Cloud and aerosol properties, precipitable water, and profiles of temperature and humidity from MODIS," IEEE Trans. Geosci. Remote Sens., 41, 442458, 2003.

[4] P. J. Webster, "The role of hydrological processes in ocean-atmosphere interactions," Rev. Geophys., 32, 427-476, 1994.

[5] F. J. Wentz, C. Gentemann, D. Smith, and D. Chelton, "Satellite measurements of sea surface temperature through clouds," Sci., 288, 847-850, 2000.

[6] B.-C. Gao, P. K. Chan, and R.-R. Li, "A global water vapor data set obtained by merging the SSMI and MODIS data," Geophys. Res. Lett., 31, 2004. 